\title{
De novo asymmetric synthesis of a 6-O-methyl-D-glycero-L-gluco- heptopyranose-derived thioglycoside for the preparation of Campylobacter jejuni NCTC11168 capsular polysaccharide fragments
}

Roger A. Ashmus, ${ }^{\dagger}$ Anushka B. Jayasuriya, ${ }^{\dagger}$ Ying-Jie Lim, ${ }^{\dagger}$ George A. O’Doherty ${ }^{\ddagger}$ and Todd L. Lowary* ${ }^{\dagger}$

${ }^{\dagger}$ Alberta Glycomics Centre and Department of Chemistry, The University of Alberta, Edmonton, Alberta T6G 2G2, Canada

*Department of Chemistry, Northeastern University, 360 Huntington Ave, Boston, MA 02115

Email: tlowary@ualberta.ca

Supporting Information

Table of Contents

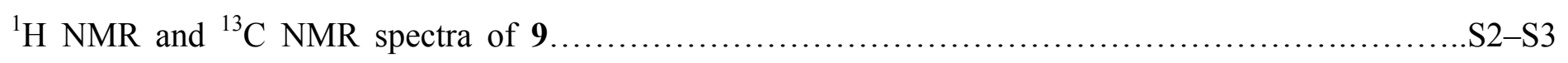

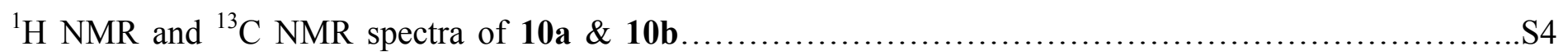

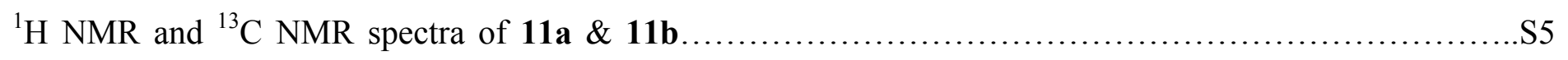

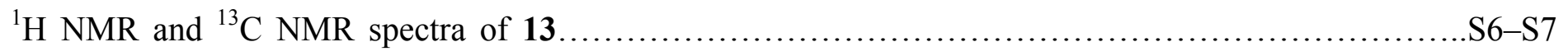

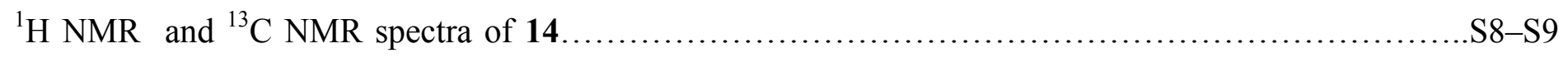

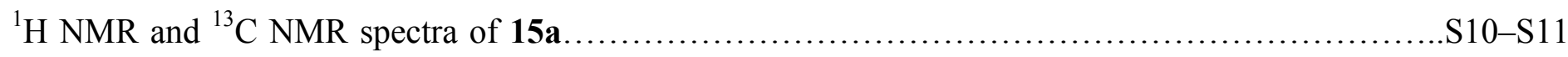

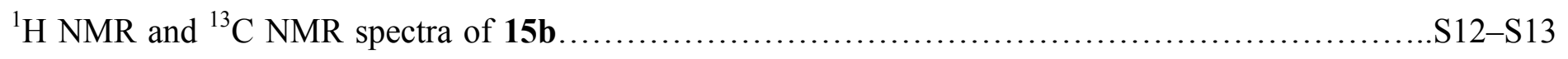

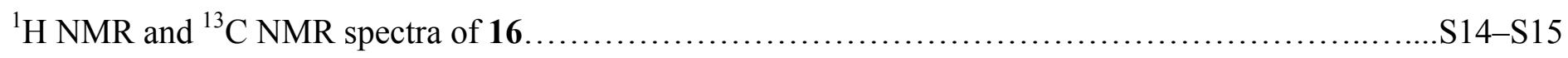




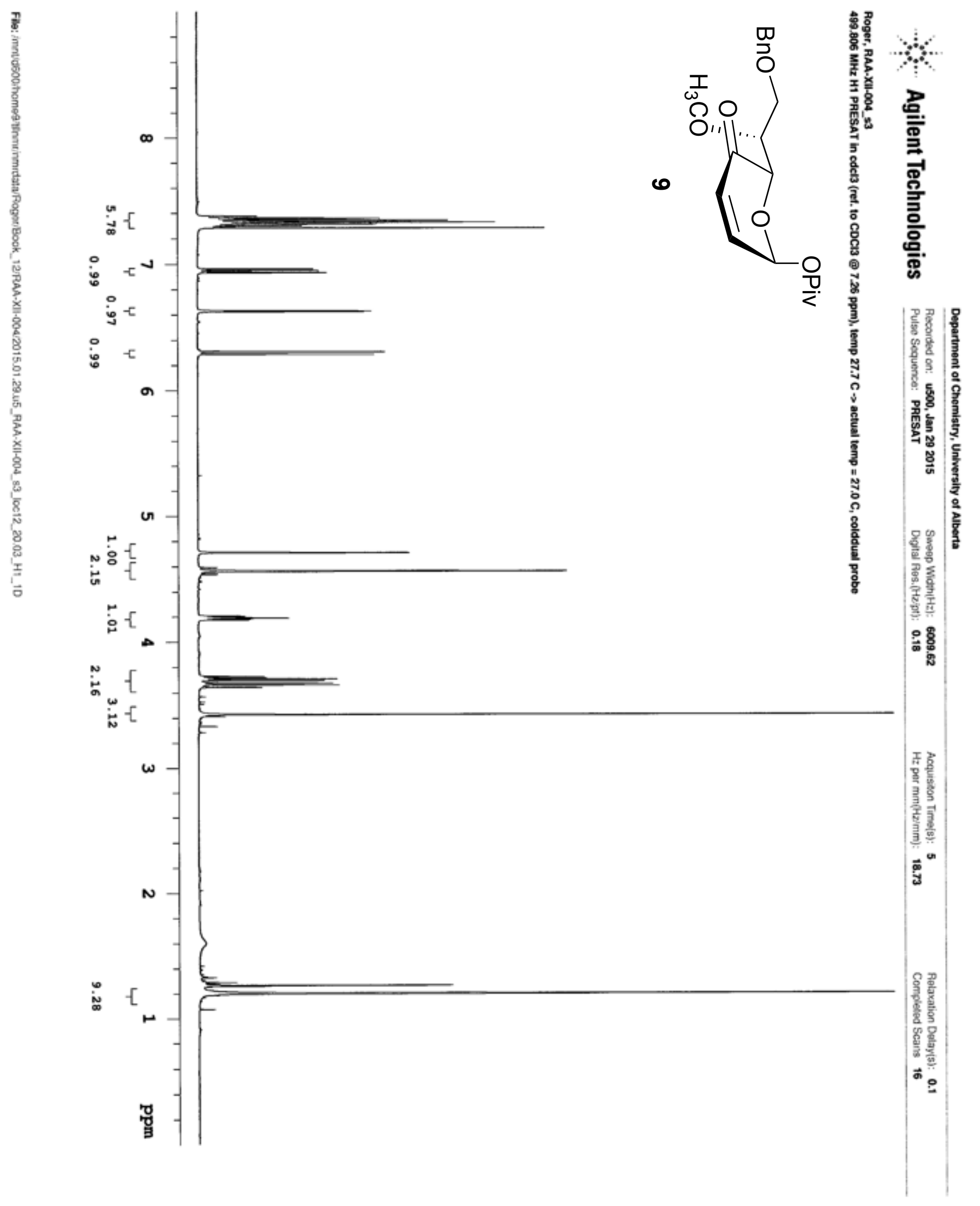




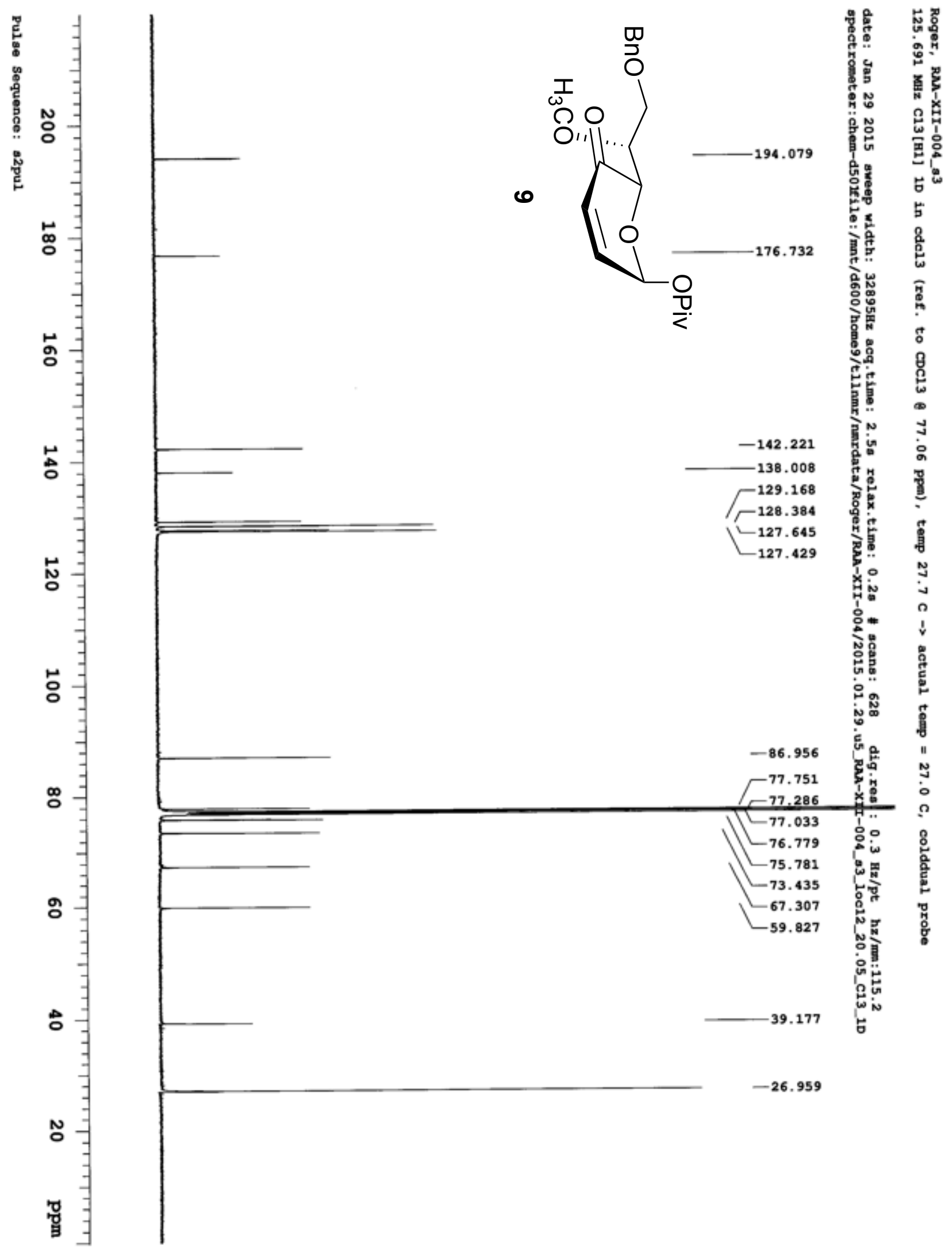




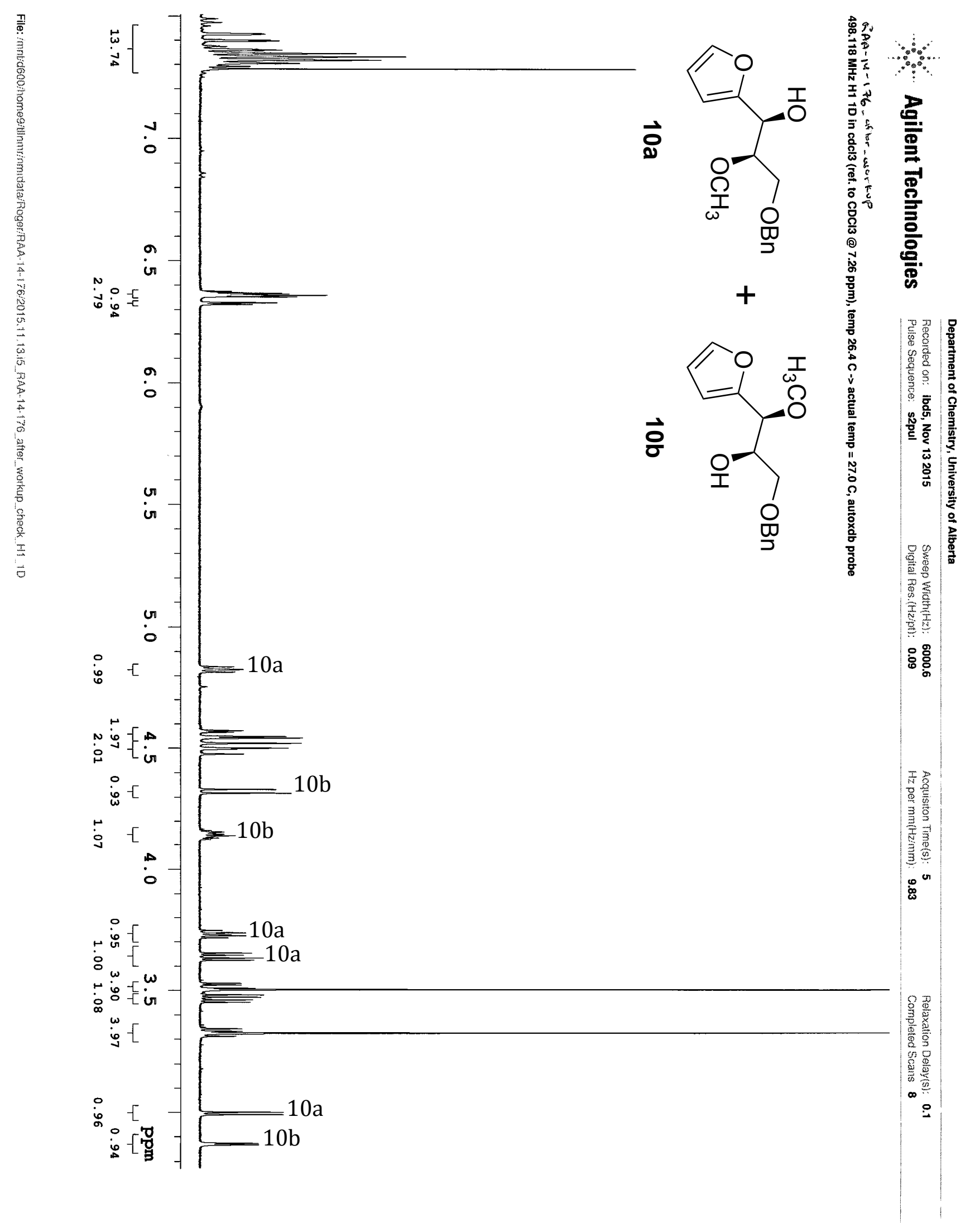




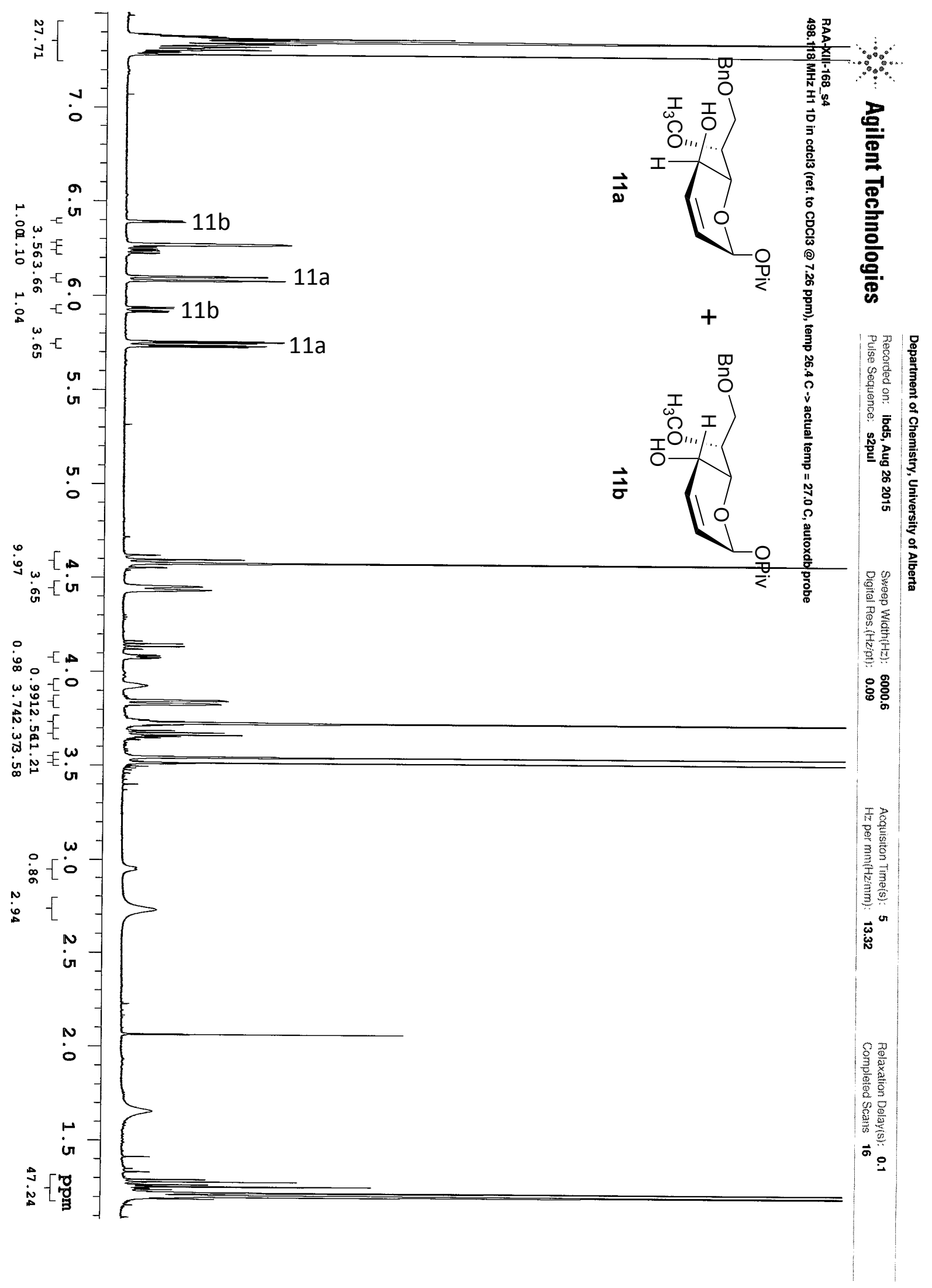




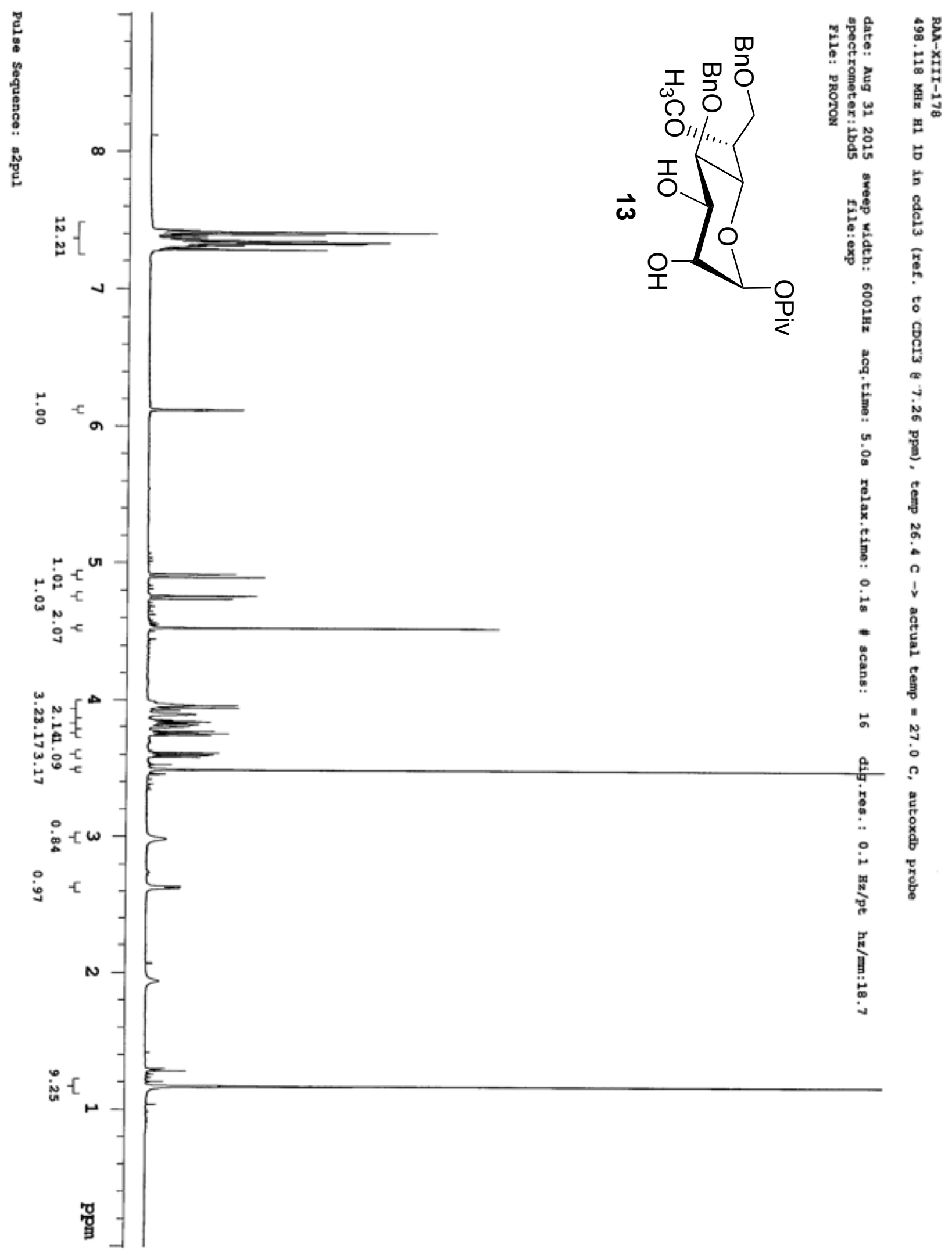




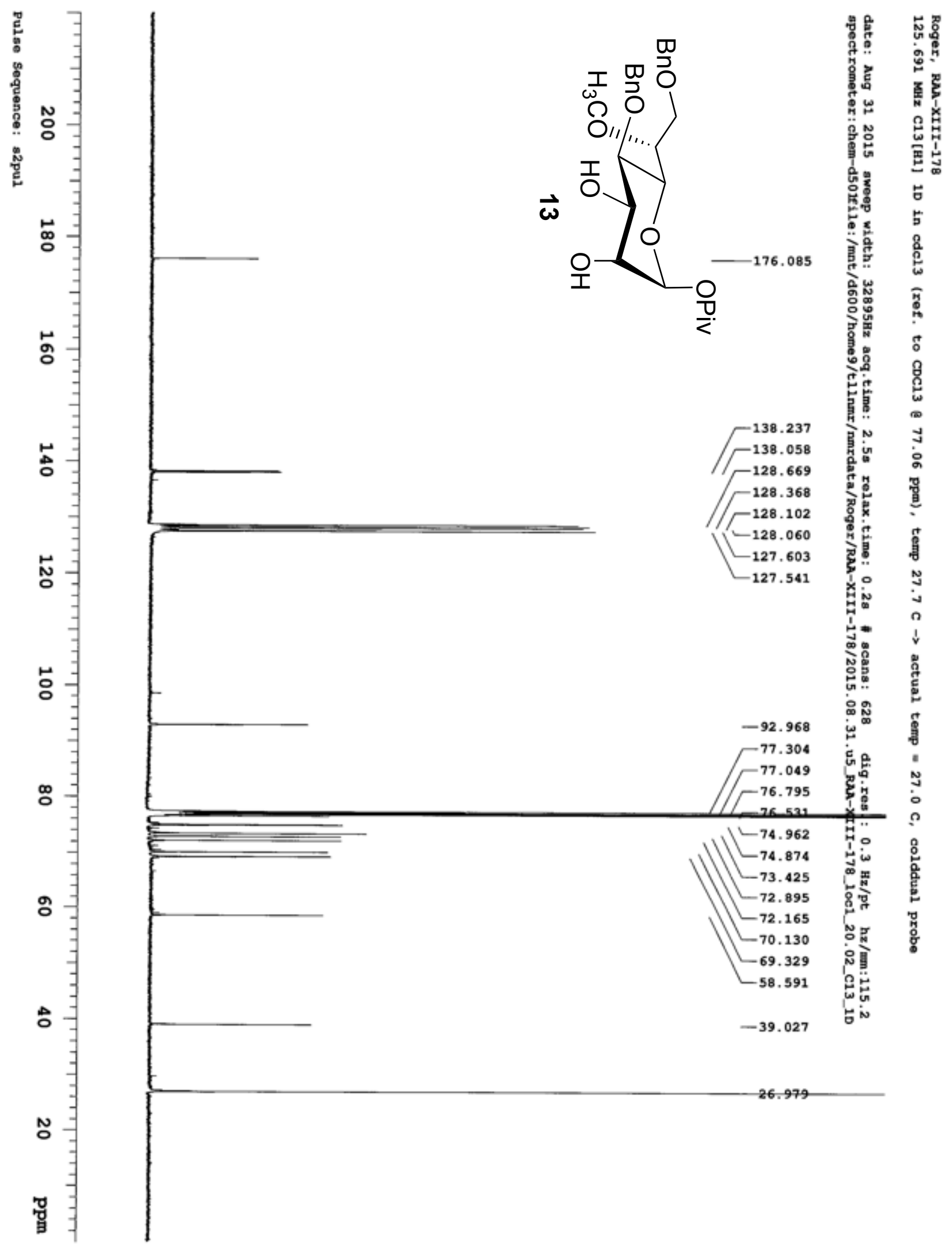




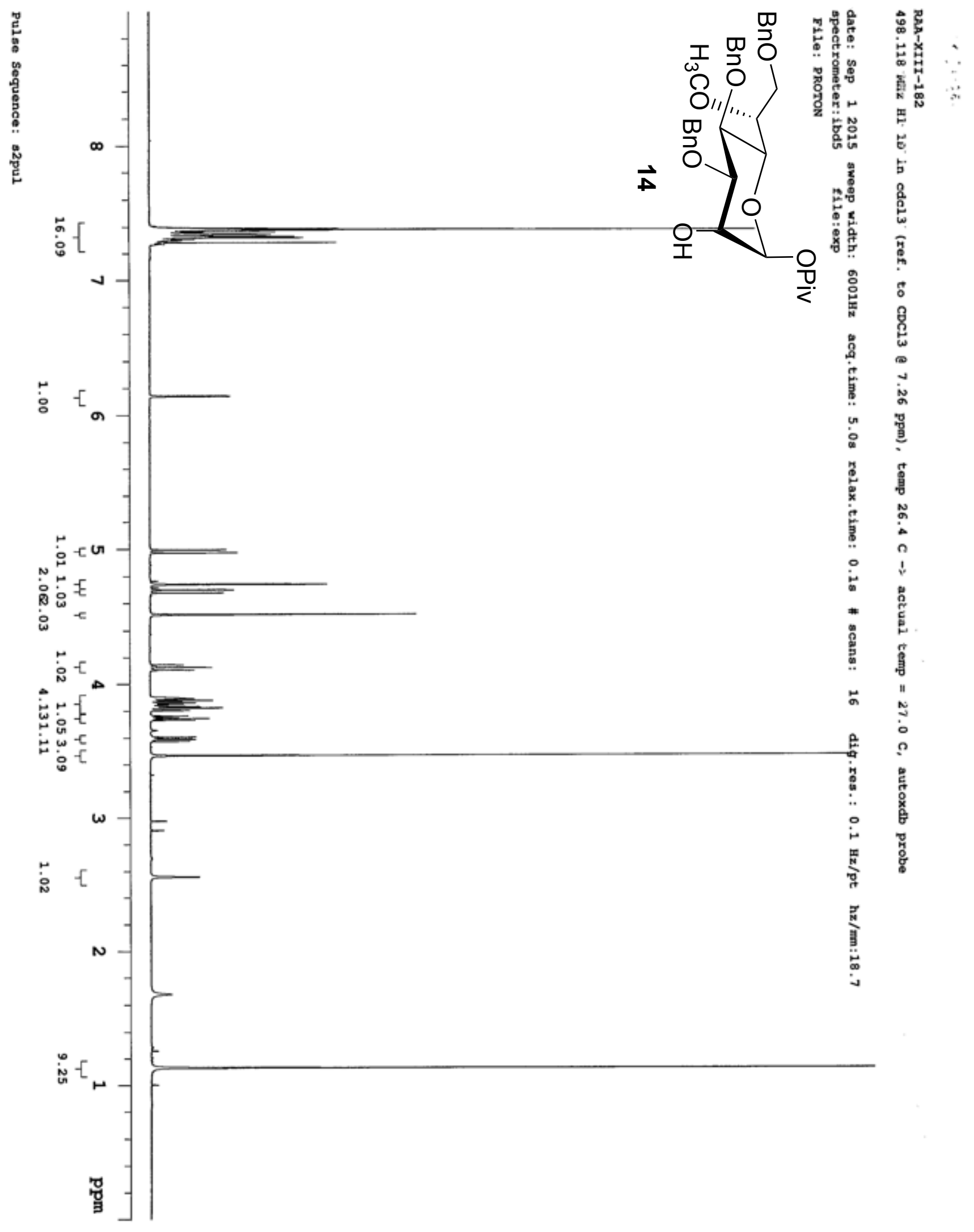




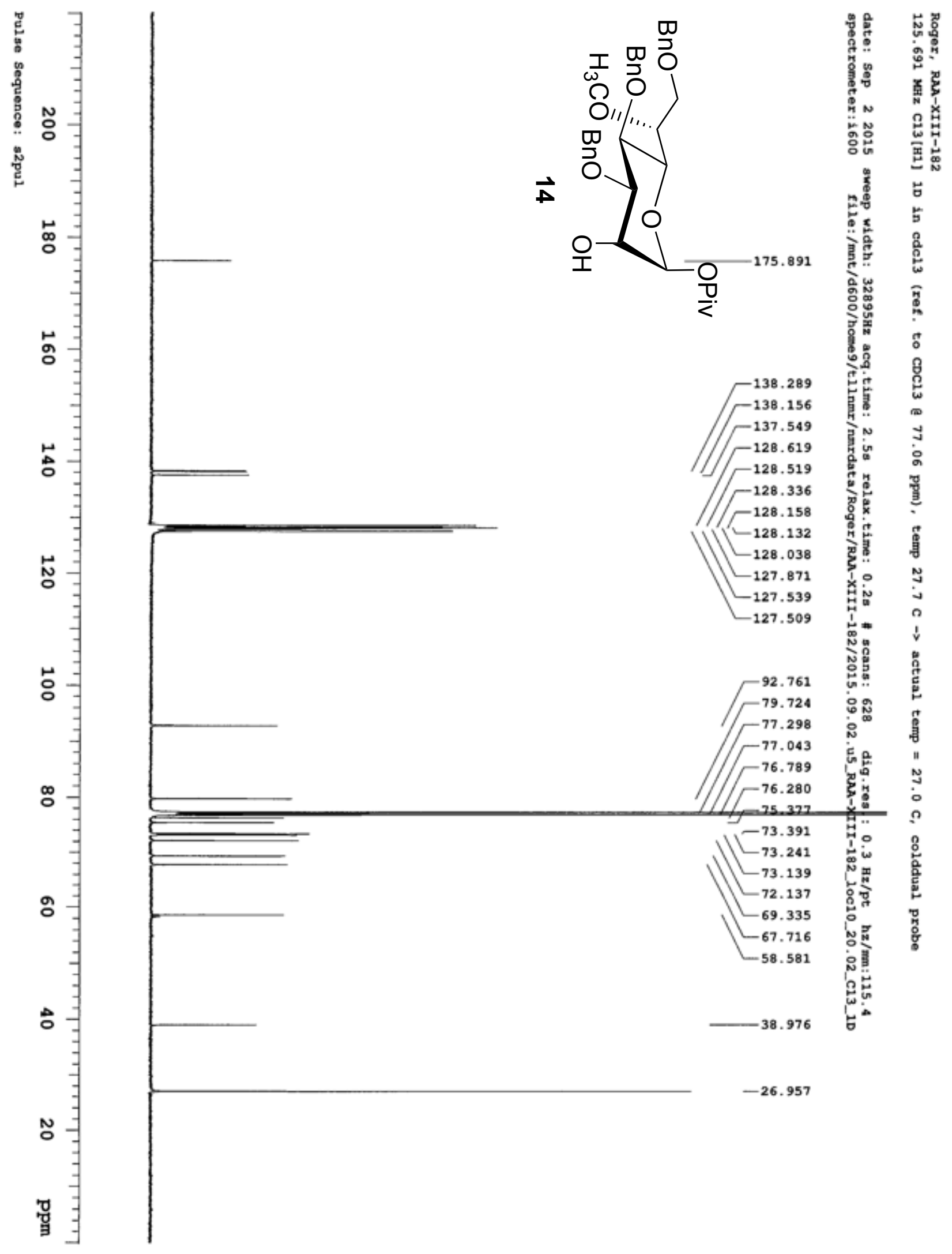




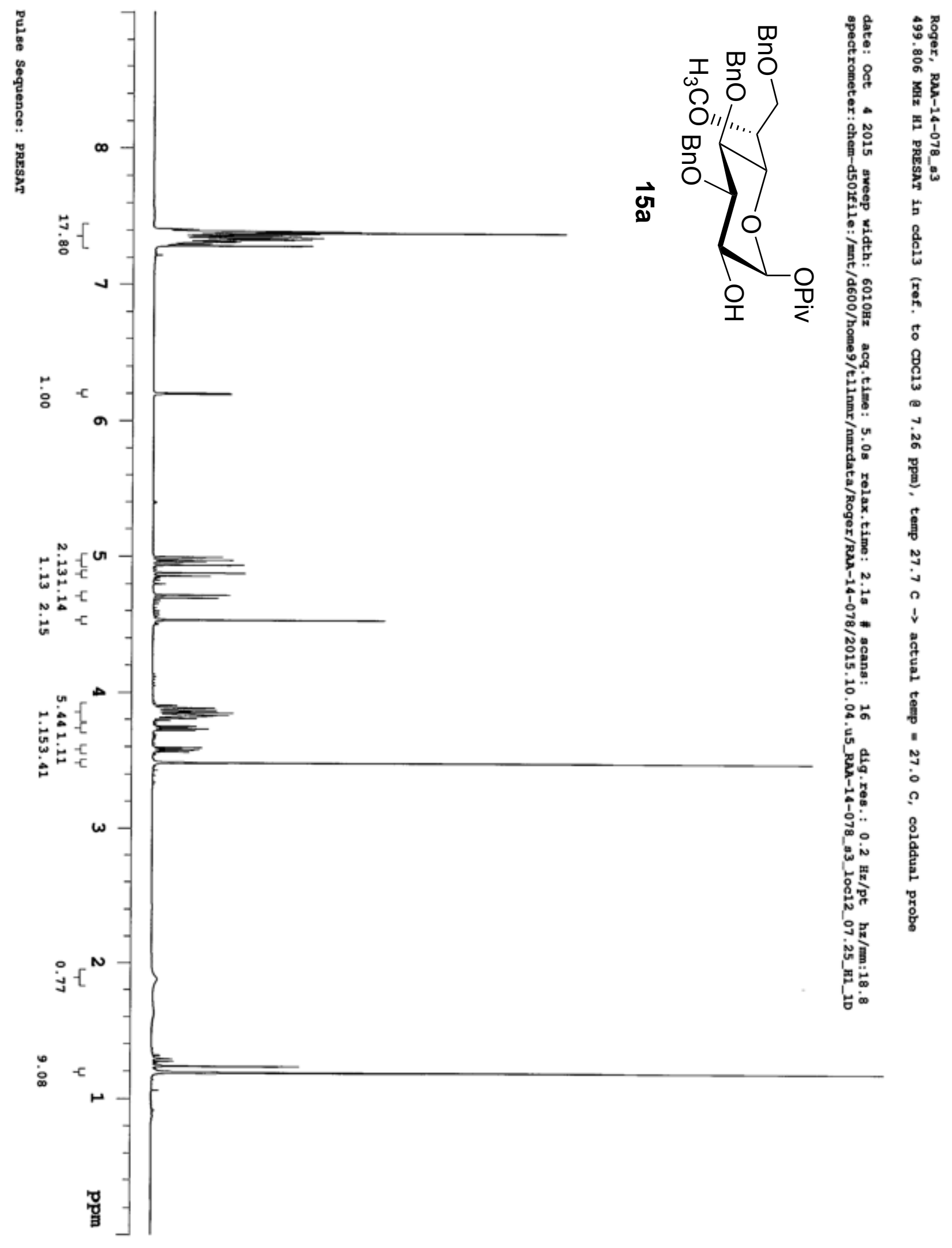




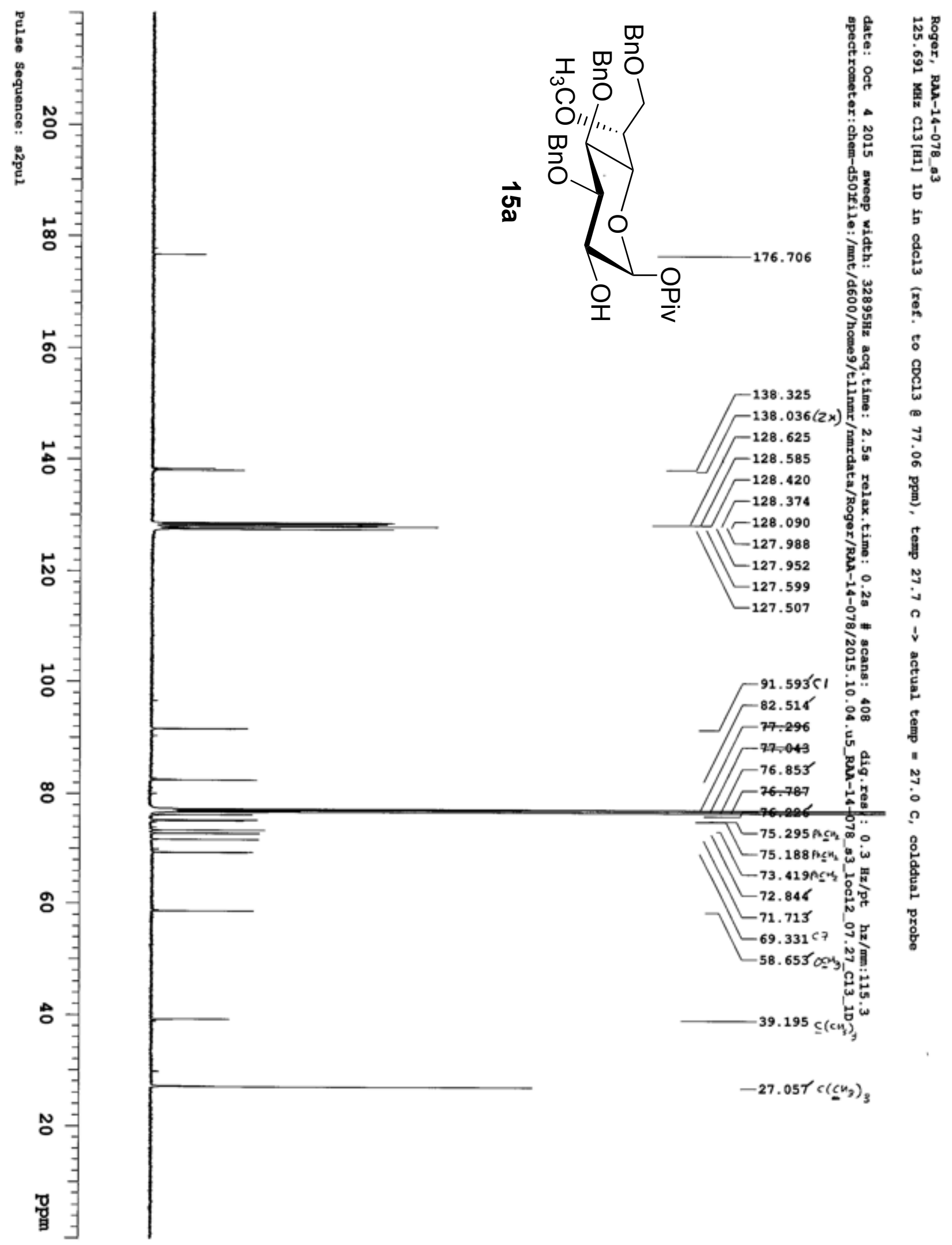




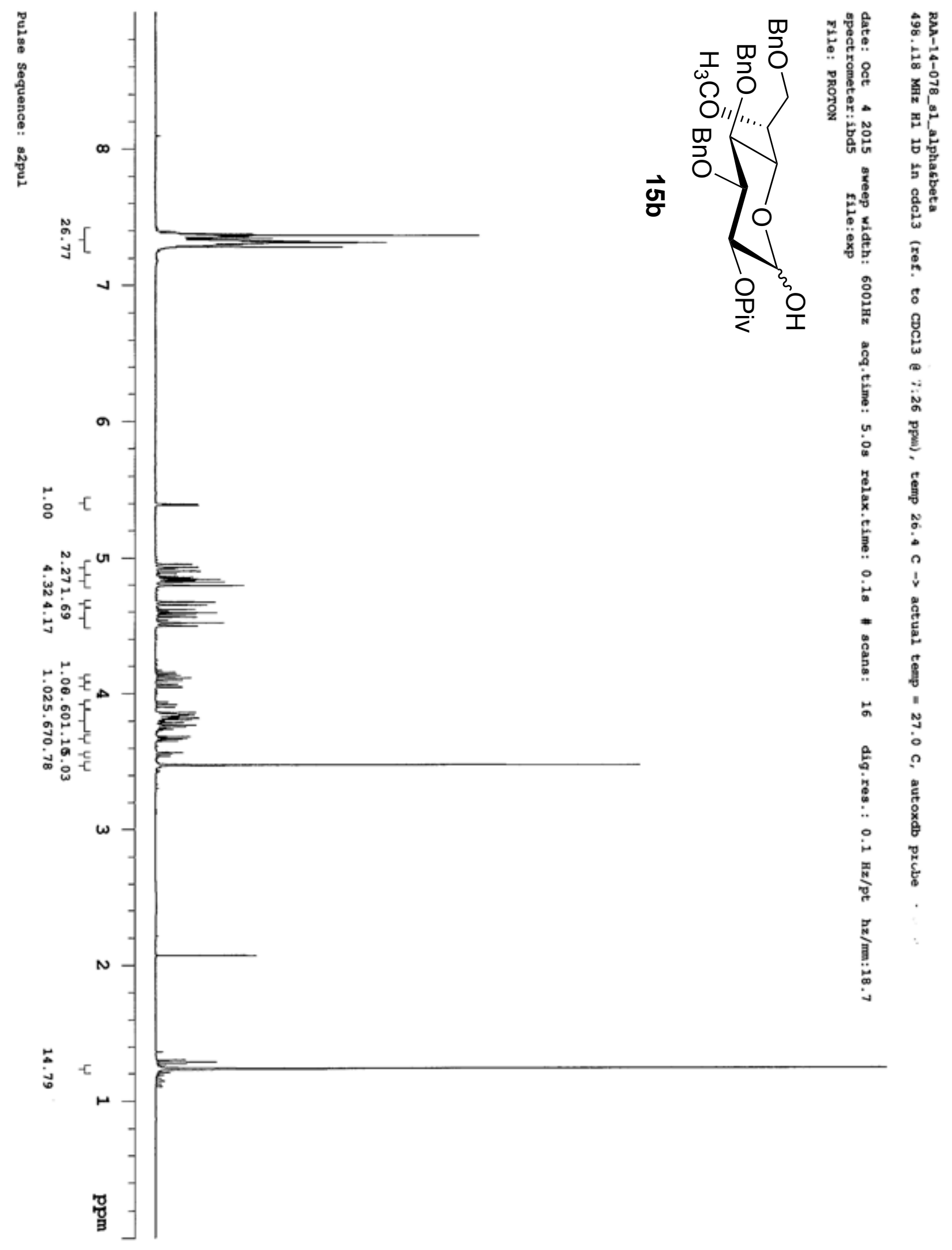




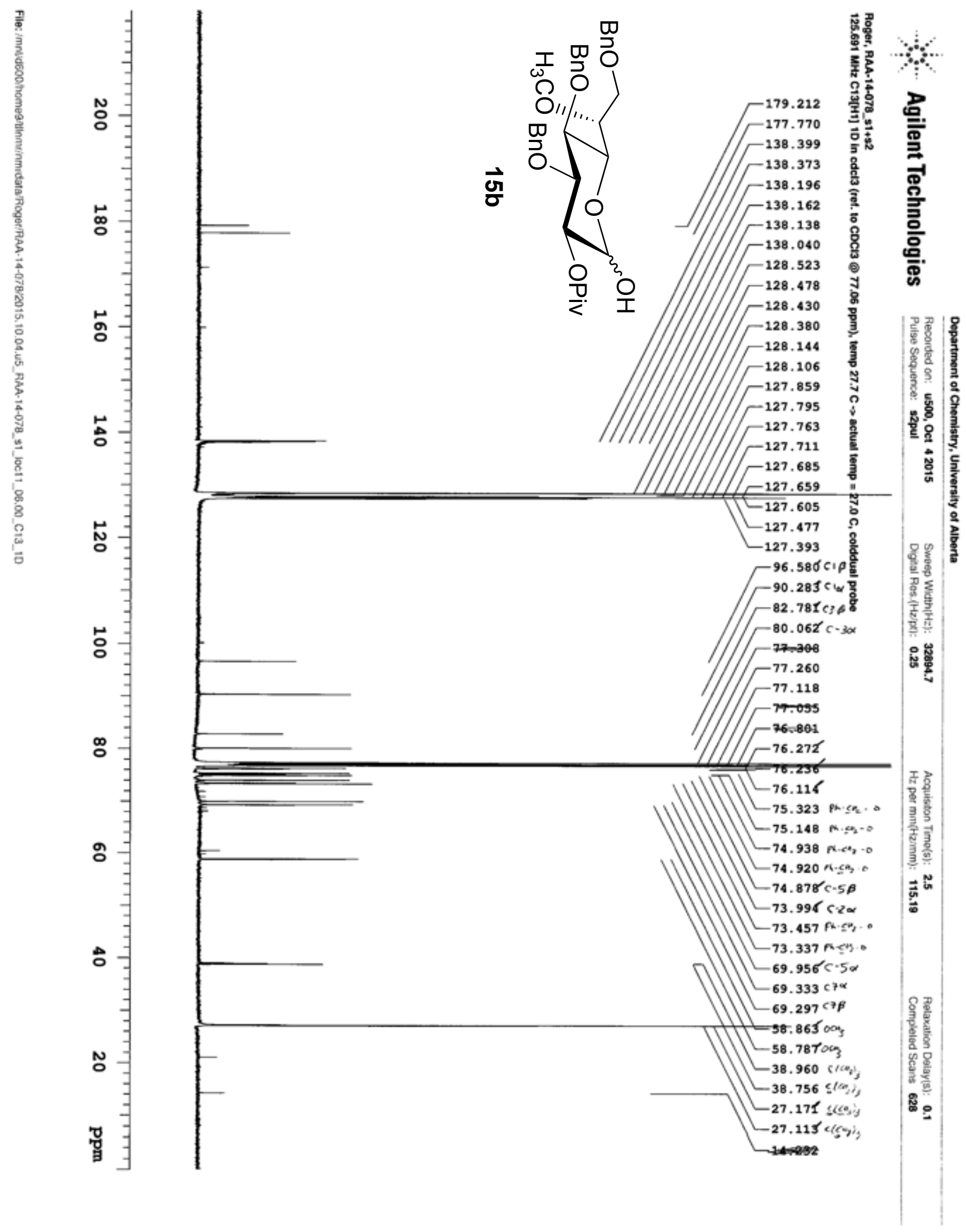




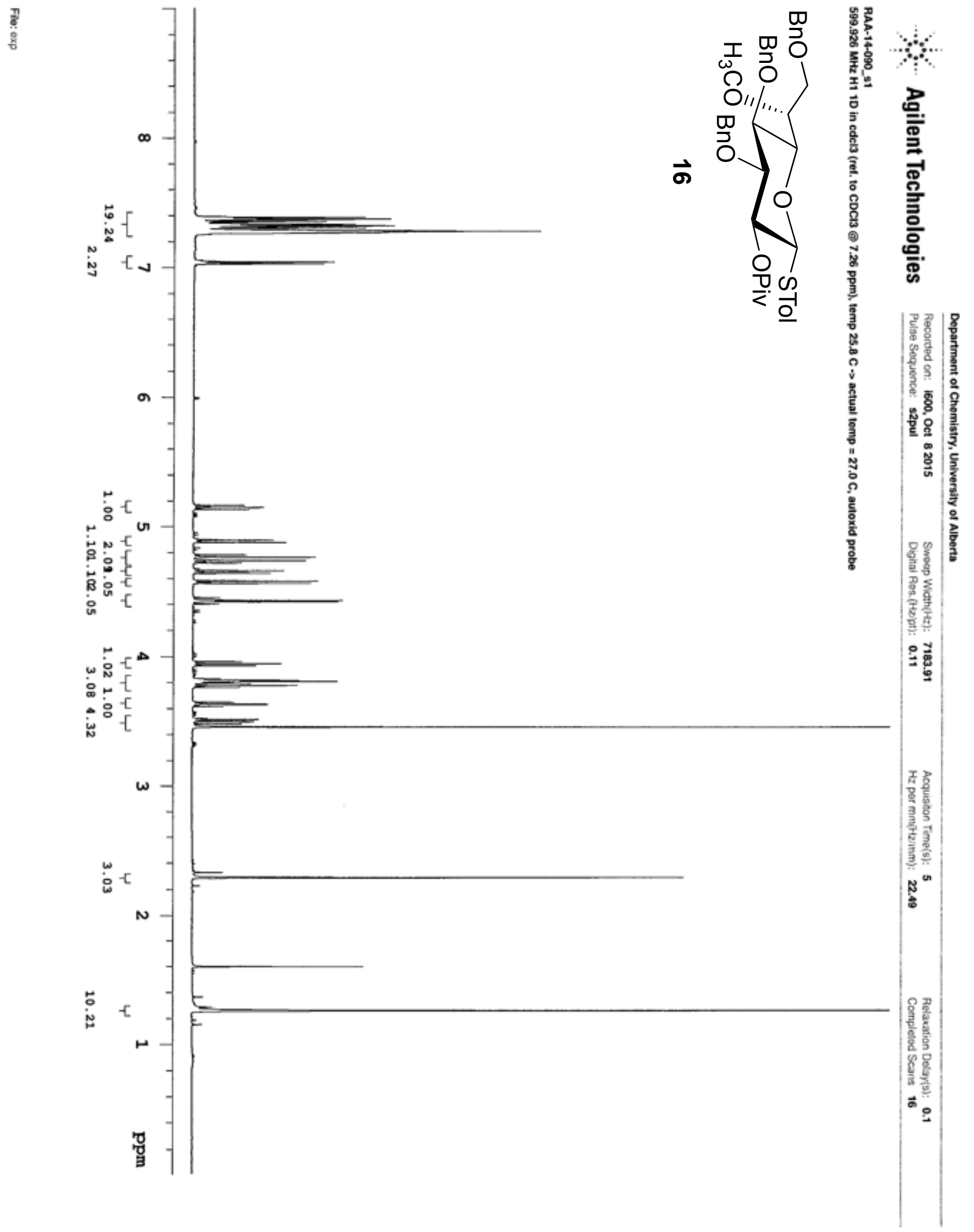




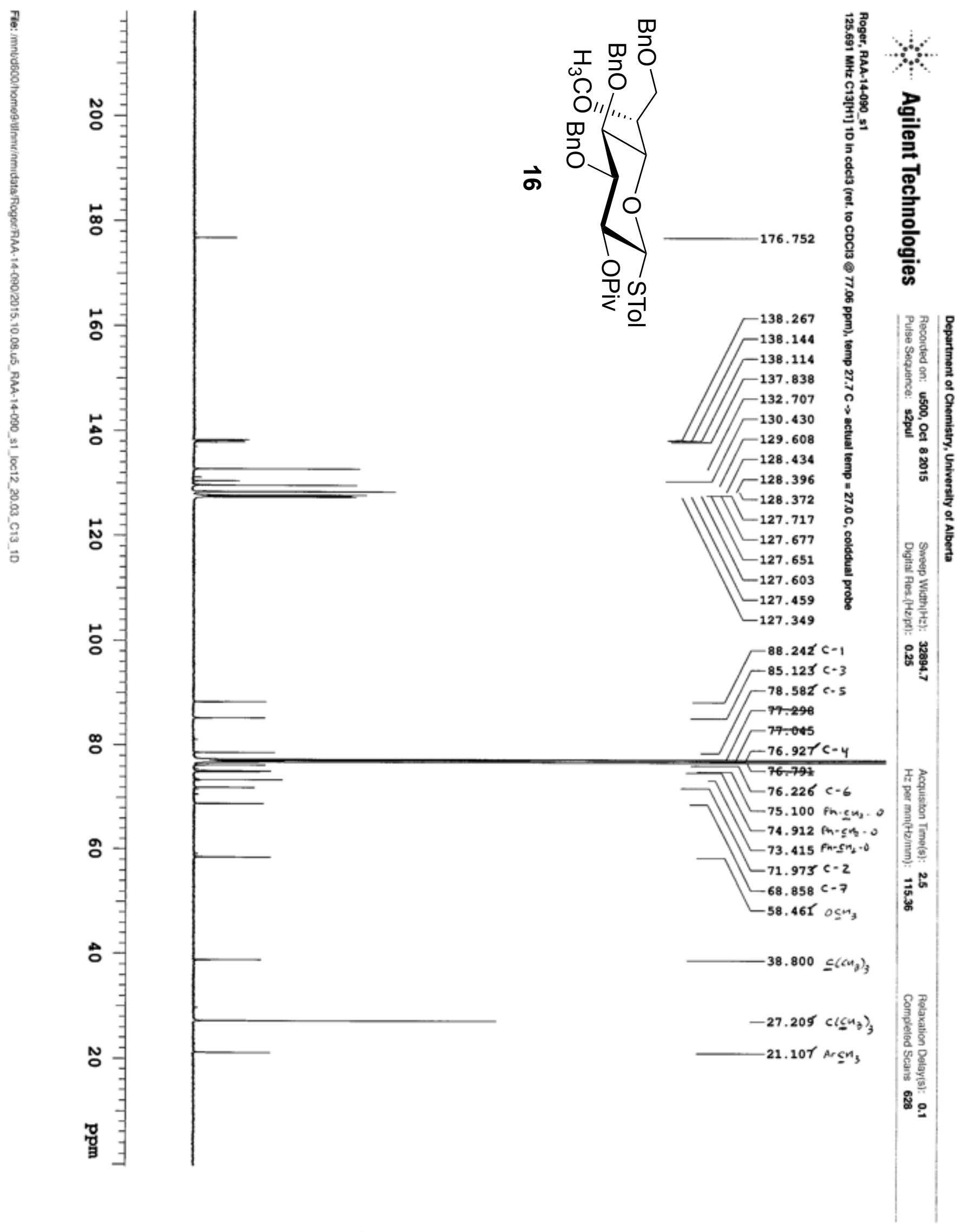

